\title{
SOLVING A CARTESIAN CONUNDRUM
}

I N A RECENT issue of this journal, Robert Oakes has proposed a "Cartesian conundrum," arguing that certain elements in Descartes' philosophical theology are incompatible. ${ }^{1}$ I believe that this conundrum can be solved. It does, however, lead to an interesting question about what constitutes the "materiality" of a material object. In this article I propose to solve the conundrum, and to say a little about that question.

The Cartesian theses which Oakes takes to be incompatible are the claims that God exists necessarily, that contingent things depend for their continued existence (perdurance) on God's conserving activity, and that there exist some (non-Berkeleyian) contingent material objects. And what is non-Berkeleyian materiality? Oakes suspects that the attempt to provide a full analysis may be "quixotic," but he provides a necessary condition: "conceivably, anything which is a material object is able to perdure without depending for such perdurance upon its having the relational 'epistemic' property of being an object of awareness." And again, such an object "lacks the property being dependent upon awareness for perdurance." (p. 146)

Given this understanding, Oakes formulates his argument as follows (p. 148):

(1) All contingent/finite things (a fortiori material things) depend for their existence-at all moments through which they perdure-upon the conserving activity of God. (subscribed to by Descartes)

(2) [] (God exists.) (subscribed to by Descartes)

(3) $\sim<$ [There exist contingent/finite things (a fortiori material things) that do not depend for their existence - at all moments through which they perdure-upon the conserving activity of God.] (from 1 and 2)

(4) [] [God (if existent) is aware of what He conserves], i.e., <> (God conserves something of which $\mathrm{He}$ is not aware.) (self-evident)

(5) [] [Whether God conserves something depends (at least in part) upon whether He is aware of it.] (from 4 and AP)

(6) $\sim<>$ (There exists a material thing that does not depend for its existence-at every moment through which it perdures - upon being an object of God's awareness.) (from 3, 4, and PTD) 
(7) $\sim<>$ (There exists a material thing that does not depend for its existence-at every moment through which it perdures-upon being an object of awareness.) ${ }^{2}$ (from 6, $a$ fortiori)

In this derivation, PTD is the claim that the relation of dependence is transitive, and AP is the claim that every state of affairs which is a necessary condition for $S$ 's obtaining is something upon which S depends.

This argument, it seems to me, is fallacious. The difficulty lies in the derivation of (3) from (1) and (2). Formally, at least, that deduction is invalid. (1) is unmodalized as it stands, and hence it is formally compatible with the supposition that it was within the power of God to create things which can perdure without His conserving activity, but that He freely chose not to create any such things. ${ }^{3}$ In that case such things would be possible, though not actual.

There are probably ways of remedying this defect. For the sake of getting to the more interesting feature of this conundrum we may as well just assume that the argument begins with (3) as a premise, rather than as a derivation.

That deeper difficulty begins with our understanding of (4), a proposition which Oakes says is self-evident. Consider first what we might call the doctrine of omniawareness:

$\left(4^{*}\right)$ [] [God (if existent) is aware of everything which exists.] Since presumably the things which God conserves constitute a subset of the things which exist one would suppose that (4) would follow from (4*). Immediately after formulating his argument however, Oakes makes a special point of denying this entailment, and of denying that his conundrum can be generated on the basis of $\left(4^{*}\right)$. And that suggests that Oakes understands (4) in terms of some "internal" relation between awareness and conserving, a relation which is not entailed by omniawareness. What might that be?

My own conjecture is that in asserting (4) Oakes really has in mind some proposition such as:

(4') [] (God's conserving of any object X depends on His awareness of X.)

And perhaps he would say that God could not conserve me in existence, for example, if He were not aware of me, presumably because without that awareness He would not be able to direct His conserving activity accurately "in my direction."

I don't know whether $\left(4^{\prime}\right)$ is self evident. In any case, however, there is something plausible about it, so perhaps we can accept it, at least tentatively. But (4') is equivalent to Oakes' (5). We can therefore think of the argument as beginning with (3) and (5) as premises. (7) does follow from these premises, and (7) appears to be incompatible with the claim that there are some (non-Berkeleyian) material objects. But this incompatibility holds only if we understand (non-Berkeleyian) materiality in Oakes' way. Perhaps we should not understand it in that way.

According to Oakes, a necessary condition of an object's being material in an "ontologically significant" (i.e., non-Berkeleyian) sense is that no element of awareness should be a necessary condition of that object's perdurance. That means that a sufficient condition of a material object's being merely Berkeleyian is that some element of awareness is necessary for that object's perdurance. But that seems highly implausible.

Of course, we can accept Oakes' necessary condition as (part of) the definition of a special class of possible objects, those which he calls "ontologically signif- 
icant." If we do that, however, we must recognize that there is no reason to suppose that this class is the complement of the class of Berkeleyian objects. There may well be a third class of objects, neither Berkeleyian nor (in Oakes' sense) "ontologically significant." Objects of this third class may well be the sort of object that Descartes was thinking about, and they may also correspond to some "ordinary" concept of what a material object is. And Oakes' argument does not show that the existence of objects of this third class is incompatible with the other elements in Descartes' philosophical theology.

To see this, think of the Berkeleyian slogan, esse est percipi. This surely does not suggest merely that percipi is a necessary condition of esse. It is rather that percipi is sufficient, as well as necessary, for esse. The esse of a Berkeleyian material object just is its percipi-perhaps a special percipi (that of God) but nothing other than percipi. There isn't anything to a Berkeleyian material object over and above God's awareness of it, and so that awareness is sufficient for the existence of such an object. We can therefore think of a kind of object which differs from a Berkeleyian object not because awareness is not a necessary condition of its existence, but rather because awareness is not sufficient for it. And it may well be that this is the sort of object which Descartes had in mind, and/ or the sort of object which corresponds to our "ordinary" concept of materiality.

If that is true, then it is possible that material objects require God's conserving action for their perdurance, and that God's conserving action requires His awareness of the object which He is conserving, and that nevertheless the objects thus conserved are Cartesian rather than Berkeleyian. God's awareness would be necessary for such objects, but it would not be sufficient for them. And it would be precisely because such objects have "something more" in them-their Cartesian materiality - that God's awareness is not sufficient to sustain them in existence. They require that God do something more than perceive them-that He perform an act of conservation-just because their esse is something more than percipi.

The University of Michigan

Ann Arbor, Michigan

\section{NOTES}

'Robert Oakes, “Material Things: a Cartesian Conundrum," Pacific Philosophical Quarterly 64 (1983) $144-150$.

${ }^{2}$ Unfortunately, the "not" in this proposition was omitted in the printed version. But it is intended by Oakes (personal communication).

${ }^{3}$ This proposition is in fact formally compatible with the stronger claim that there are two objects which have all of their essential properties in common, but which differ from each other in that one requires, and the other does not, the conserving action of God for its perdurance. 